\title{
Population Pharmacokinetics of Intravenous Salbutamol in Children with Refractory Status Asthmaticus
}

\author{
Nienke J. Vet ${ }^{1}$ (D) Brenda C. M. de Winter ${ }^{2} \cdot$ Muriel Koninckx $^{3}$ - Shelley A. Boeschoten ${ }^{1}$ - Annemie L. M. Boehmer ${ }^{4}$. \\ Jacintha T. Verhallen ${ }^{5}$. Frans B. Plötz ${ }^{6}$ Anja A. Vaessen-Verberne ${ }^{7}$ Bart C. H. van der Nagel ${ }^{2}$. \\ Catherijne A. J. Knibbe ${ }^{8} \cdot$ Corinne M. P. Buysse $^{1} \cdot$ Saskia N. de Wildt ${ }^{1,9} \cdot$ Birgit C. P. Koch $^{2} \cdot$ Matthijs de Hoog ${ }^{1}$
}

Published online: 21 August 2019

(c) The Author(s) 2019

\begin{abstract}
Background Intravenous salbutamol is used to treat children with refractory status asthmaticus, however insufficient pharmacokinetic data are available to guide initial and subsequent dosing recommendations for its intravenous use. The pharmacologic activity of salbutamol resides predominantly in the (R)-enantiomer, with little or no activity and even concerns of adverse reactions attributed to the $(\mathrm{S})$-enantiomer.

Objective Our aim was to develop a population pharmacokinetic model to characterize the pharmacokinetic profile for intravenous salbutamol in children with status asthmaticus admitted to the pediatric intensive care unit (PICU), and to use this model to study the effect of different dosing schemes with and without a loading dose.

Methods From 19 children (median age 4.9 years [range 9 months-15.3 years], median weight $18 \mathrm{~kg}$ [range $7.8-70 \mathrm{~kg}$ ]) treated with continuous intravenous salbutamol at the PICU, plasma samples for R- and S-salbutamol concentrations (111 samples), as well as asthma scores, were collected prospectively at the same time points. Possible adverse reactions and patients' clinical data (age, sex, weight, drug doses, liver and kidney function) were recorded. With these data, a population pharmacokinetic model was developed using NONMEM 7.2. After validation, the model was used for simulations to evaluate the effect of different dosing regimens with or without a loading dose.

Results A two-compartment model with separate clearance for R- and S-salbutamol $(16.3 \mathrm{~L} / \mathrm{h}$ and $8.8 \mathrm{~L} / \mathrm{h}$, respectively) best described the data. Weight was found to be a significant covariate for clearance and volume of distribution. No other covariates were identified. Simulations showed that a loading dose can result in higher R-salbutamol concentrations in the early phase after the start of infusion therapy, preventing accumulation of S-salbutamol.

Conclusions The pharmacokinetic model of intravenous R- and S-salbutamol described the data well and showed that a loading dose should be considered in children. This model can be used to evaluate the pharmacokinetic-pharmacodynamic relationship of intravenous salbutamol in children, and, as a next step, the effectiveness and tolerability of intravenous salbutamol in children with severe asthma.
\end{abstract}

Nienke J. Vet and Brenda C. M. de Winter contributed equally to this work.

Electronic supplementary material The online version of this article (https://doi.org/10.1007/s40262-019-00811-y) contains supplementary material, which is available to authorized users.

Nienke J. Vet

n.vet@erasmusmc.nl

Extended author information available on the last page of the article

\section{Key Points}

In this prospective study, we developed a population pharmacokinetic model of intravenous R- and S-salbutamol in children with status asthmaticus admitted to the intensive care unit.

The model described the data well and showed that a loading dose seems valid to reach higher initial R-salbutamol concentrations with a possible therapeutic advantage.

This model can be used to evaluate the pharmacokinetic-pharmacodynamic relationship of intravenous salbutamol. 


\section{Introduction}

Asthma exacerbations are a frequent cause of hospitalization among children, with admissions for refractory status asthmaticus to intensive care increasing over the last years [1, 2]. The pathologic hallmarks of asthma are bronchoconstriction, airway inflammation, and mucus plugging, all of which may lead to severe airflow obstruction.

The initial therapy of status asthmaticus includes oxygen, repetitive administration of inhaled $\beta 2$-agonists and ipratropium, and systemic corticosteroids. The aim of these treatments is to improve airflow obstruction and hypoxemia as quickly as possible. For patients who do not respond to initial therapy, magnesium sulphate, aminophylline and intravenous salbutamol are suggested [3]. Depending on local or national guidelines, intravenous salbutamol is used as second- or third-line treatment. Intensive care admission is often needed for continuous monitoring [3, 4]. Intravenous salbutamol may be more effective in severe asthma as delivery of inhaled drugs to airways may be attenuated and unpredictable as a result of severe airflow obstruction [5].

Salbutamol (albuterol) is a selective $\beta 2$-adrenoreceptor agonist with potent smooth muscle relaxant properties, and is a chiral compound with ( $\mathrm{R})$ - and $(\mathrm{S})$-enantiomers. The pharmacologic activity of salbutamol resides predominantly in the (R)-enantiomer, with little or no activity attributed to the (S)-enantiomer [6]. Moreover, there are concerns that particularly high exposure to $\mathrm{S}$-salbutamol may have negative effects. The primary route of elimination of salbutamol is by sulfate conjugation (SULT1A3), followed by renal excretion. Up to $50 \%$ of salbutamol is excreted unchanged in urine [7]. The elimination of (R)-salbutamol is much more rapid than that of $(\mathrm{S})$-salbutamol, which leads to relatively higher plasma concentrations of $(\mathrm{S})$-salbutamol with the same continuous infusion [8].

Although intravenous salbutamol is often used in children, pharmacokinetic (PK) data are scarce. Dosing recommendations are not based on well-conducted PK and pharmacodynamic (PD) studies and, as a result, guidelines are inconsistent with respect to salbutamol dosing in children. Dosing of intravenous salbutamol in children varies between 0.1 and $10 \mu \mathrm{g} / \mathrm{kg} / \mathrm{min}$ and there is no consensus on the need for a loading dose at the start of therapy [9-11]. Compared with adult dosing, these recommendations are higher and might lead to toxic serum concentrations. PK data are needed to guide initial and subsequent dosing recommendations for intravenous salbutamol in children. Therefore, the aim of this study was to develop a population PK model to characterize the PK profile for intravenous salbutamol in children with status asthmaticus admitted to the intensive care unit.

\section{Methods}

\subsection{Patients and Setting}

For this PK study, patients were recruited from Erasmus MC-Sophia Children's Hospital's pediatric intensive care unit (PICU), a tertiary PICU in The Netherlands. Approval was obtained from the Institutional Review Board, along with written informed consent from parents or legal representatives and patients (12-18 years).

Eligible patients were children with status asthmaticus aged between 0 and 18 years of age who were admitted to the PICU because of respiratory distress and who required intravenous salbutamol. Those patients requiring extracorporeal membrane oxygenation were excluded from the study.

Patients were treated according to our institutional clinical protocol for status asthmaticus (electronic supplementary Appendix I). A continuous salbutamol infusion was started at a rate of $0.1 \mu \mathrm{g} / \mathrm{kg} / \mathrm{min}$. Subsequently, the infusion rate was increased every 10 min depending on clinical symptoms (wheezing, dyspnoe, saturation) and asthma score, with a maximum infusion rate of $10 \mu \mathrm{g} / \mathrm{kg} / \mathrm{min}$ (electronic supplementary Appendix I).

\subsection{Measurements}

Blood for salbutamol concentrations was sampled using an optimized sampling strategy for PK analysis. Ideally, the first blood sample was taken before the start of intravenous salbutamol (plasma drug level after inhaled salbutamol only), but because of the acute setting at admission to the Emergency Department or PICU, and no informed consent having been received at that point in time, the first blood sample was only available if leftover material taken from clinical care was available. During the infusion of salbutamol, serial blood samples were taken at time points of 10 , 15-30, 40-60 min, 2-4, 4-6 and 8-16 h after an infusion rate change. Further samples were taken prior to discontinuation, as well as 10, 30-60 min, 2-6 and 12-24 h after discontinuation of the infusion. Blood $(0.5 \mathrm{~mL})$ was drawn from an indwelling arterial line or central venous catheter, or, in case this was not available, together with peripheral blood sampling for clinical purposes. Plasma samples were analysed for R- and S-salbutamol concentrations separately using a validated liquid chromatography-tandem mass spectrometry (LC-MS/MS) method; the limit of quantification of the method was $1.0 \mu \mathrm{g} / \mathrm{L}$, with a linearity of between 1.0 and $500 \mu \mathrm{g} / \mathrm{L}$ for both R- and S-salbutamol (electronic supplementary Appendix II).

As a PD parameter, the Qureshi asthma score was collected at the same time points as blood sampling. This validated score is routinely used in the intensive care unit to 
monitor symptom progression [12, 13]. It is a 5-item scale (breathing frequency [categories for age], oxygen saturation, auscultation, retractions and dyspnea), with a minimum of 1 and maximum of 3 for each item, resulting in a range of 5-15. A higher score indicates a more severe exacerbation. Possible adverse reactions from salbutamol, such as tachycardia, arrhythmias, hypotension, hypokalemia, hyperglycemia and lactic acidosis were recorded.

Furthermore, age, bodyweight, sex, diagnosis, drug doses, and available kidney and liver function indices were collected for all patients from our computer-based patient data management system.

\subsection{Population Pharmacokinetic (PK) Model}

The population PK model was developed using nonlinear mixed-effects modelling (NONMEM, version 7.2; ICON Development Solutions, Ellicott City, MD, USA). The analysis was performed using logarithmically transformed concentrations and the first-order conditional estimation method with interaction (FOCE-I) [ADVAN5 TRANS1]. Tools used to evaluate and visualize the model were RStudio (version 0.98.1049), R (version 3.1.2), XPose (version 4.5.3) and PsN (version 4.6.0), all with the graphical interface Pirana (version 2.9.0) [14].

Model development was a three-step process: (1) selection of a structural and error model; (2) covariate analysis; and (3) internal validation of the model.

In the first step, a structural model was developed to describe the PK of R- and S-salbutamol. The salbutamol concentration before the start of the intravenous concentration related to the inhalation therapy was estimated based on the available data. The concentration at this time was estimated assuming an equal distribution between R- and S-salbutamol. For each patient, the baseline concentration was estimated using a parameter for the baseline dose, with interpatient variability (IPV). To determine the structural PK model, one- and two-compartment models were tested for both enantiomers. PK parameters were estimated in terms of central volume of distribution $\left(V_{\mathrm{c}}\right)$, peripheral volume of distribution $\left(V_{\mathrm{p}}\right)$, clearance $(\mathrm{CL})$, and intercompartmental clearance $(Q)$. For each parameter, it was determined whether the parameter could be estimated for both enantiomers together, or whether it had to be estimated separately. To account for the variability in PK parameters due to the varying size of the individual children, the parameter values were standardized to a body weight of $70 \mathrm{~kg}$ using allometric scaling, in which the exponential parameter was initially fixed at a value of 0.75 for $\mathrm{CL}$ and $\mathrm{Q}$, and a value of 1 for the volumes of distribution [15]. During the covariate analysis, it was evaluated whether estimation of the exponent improved the goodness of fit. The addition of IPV, described using an exponential model, was evaluated for each PK parameter. Residual variability between observed and predicted plasma concentrations was described using an additional error model for logarithmically transformed data.

Once the base model was selected, covariates were tested for their influence on PK parameters. Covariates tested were bodyweight (estimation of exponent for allometric scaling), age, sex, creatinine, alanine transaminase, and urea concentrations. Continuous covariates were normalized to the population median and modeled using an exponential model, while categorical variables were modelled proportionally. Covariates were included using forward inclusion $(p<0.05)$ and backward elimination $(p>0.001)$. Additional criteria for the inclusion of covariates in the model were graphical evaluation of the parameter-covariate relationship and decrease in the IPV of the parameter involved.

The minimum objective function value (OFV) was used as a criterion for model selection. If the difference between two nested models was larger than the critical value from a Chi-square distribution with degrees of freedom equal to the difference in the number of estimated parameters, the models were significantly different from each other. A decrease in OFV $>10.83$ showed a significant improvement of a nested model with one degree of freedom of $p<0.001$. Model adequacy was further evaluated using various residual plots ('goodness-of-fit' plots) stratified for age groups $<5,5-10$ and $>10$ years, and values of random-effects variances.

The final model was validated using normalized prediction distribution errors (NPDEs), using 2000 simulated datasets. This is a simulation-based diagnostic, which can be used to evaluate models developed on datasets with variable dosing regimens.

\subsection{Dose Simulations}

After validation, the model was used for simulations to evaluate the effect of different dosing regimens with or without a loading dose. The R- and S-salbutamol concentrations were simulated using the final model for a typical child weighing $15 \mathrm{~kg}$. As a result of salbutamol inhalation therapy, a concentration of approximately $20 \mu \mathrm{g} / \mathrm{L}$ was observed just before the start of the intravenous administration. The intravenous salbutamol administration is started as well as this salbutamol concentration, which is described by the model using the baseline dose. The intravenous infusion rate in the first 10 min varied between 0.5 (no loading dose) and $1.5 \mu \mathrm{g} /$ $\mathrm{kg} / \mathrm{min}$ (with loading dose), followed by a continuous infusion of $0.5 \mu \mathrm{g} / \mathrm{kg} / \mathrm{min}$ for the following $6 \mathrm{~h}$. 


\section{Results}

\subsection{Patients and Data}

Salbutamol concentrations were obtained from 19 children treated with intravenous salbutamol at the PICU between September 2011 and February 2013. Patients were between 9 months and 15 years of age (median 4.9 years) and body weight ranged from 7.8 to $70 \mathrm{~kg}$ (median $18 \mathrm{~kg}$ ) (see Table 1).

A total of 117 plasma samples were analyzed for R- and S-salbutamol. In 8 of the 117 samples obtained from seven different patients, extremely high concentrations of both enantiomers were measured. Six of these concentrations could be explained due to skin contamination of fingerprick blood after nebulizing salbutamol [16]. These samples were subsequently removed from the database, resulting in a final dataset containing 111 samples (median of three samples per patient, range 1-22).

For eight patients, plasma samples were taken during inhalational salbutamol therapy and shortly before the start of intravenous salbutamol. The median plasma level of R-salbutamol ( $n=8$ ) was $24.5 \mu \mathrm{g} / \mathrm{L}$ (range 7-60 $\mu \mathrm{g} / \mathrm{L}$ ), and $49 \mu \mathrm{g} / \mathrm{L}$ (range 31-94 $\mu \mathrm{g} / \mathrm{L}$ ) for S-salbutamol. Median plasma levels during intravenous salbutamol were $66 \mu \mathrm{g} / \mathrm{L}$ (range 4-969 $\mu \mathrm{g} / \mathrm{L}$ ) for R-salbutamol and $108 \mu \mathrm{g} / \mathrm{L}$ (range 19-1094 $\mu \mathrm{g} / \mathrm{L}$ ) for S-salbutamol (see electronic supplementary material 1). The median dose range was $0.96 \mu \mathrm{g} /$ $\mathrm{kg} / \mathrm{min}$ (range $0.07-10 \mu \mathrm{g} / \mathrm{kg} / \mathrm{min}$ ), and the maximum dose of $10 \mu \mathrm{g} / \mathrm{kg} / \mathrm{min}$ was administered to two patients. The median duration of intravenous therapy was $22.5 \mathrm{~h}$ (range 7.6-192.5 h). Asthma scores were between 5 and 15, with a median score of 8 during the whole study period. At the time when patients were sickest, the median score was 12 (range 9-15). No simple graphical correlation between asthma scores and salbutamol concentration was found, and no major adverse reactions were reported.

Table 1 Patient characteristics $(n=19)$

\begin{tabular}{llc}
\hline Parameter & Median & Range \\
\hline Age (years) & 4.9 & $0.8-15.3$ \\
Bodyweight $(\mathrm{kg})$ & 18 & $7.8-70$ \\
Sex $($ male/female) & $14 / 5$ & \\
Creatinine $(\mu \mathrm{mol} / \mathrm{L})$ & 29 & $17-70$ \\
Alanine transaminase $(\mathrm{IU} / \mathrm{L})$ & 15 & $5-26$ \\
Urea $(\mathrm{mmol} / \mathrm{L})$ & 3.2 & $1.6-4.8$ \\
Salbutamol intravenous dose $(\mu \mathrm{g} / \mathrm{kg} / \mathrm{min})$ & 0.96 & $0.07-10$ \\
Duration of intravenous salbutamol $(\mathrm{h})$ & 22.5 & $7.6-192.5$ \\
\hline
\end{tabular}

\subsection{Population PK Model}

Data could best be described using a two-compartment model, with separated clearances for R- and S-salbutamol (Fig. 1). Immediately after infusion, salbutamol is divided towards two central compartments $\left(k=10 \mathrm{~h}^{-1}\right.$ fixed), with equal volumes of distribution of $12.9 \mathrm{~L}$ for both enantiomers. The covariate analysis showed that body weight was a significant covariate using a power function. The exponent of the power function was fixed at 0.75 for clearance and $Q$, and at 1 for $V_{\mathrm{c}}$ and $V_{\mathrm{p}}$. Estimation of the exponent resulted in similar values and did not improve the model. The parameter estimations are presented in Table 2. No other covariates resulted in a significant improvement of the model. Goodness-of-fit plots showed a good fit of the model (Fig. 2). This final model resulted in a $\mathrm{CL}_{\mathrm{R} \text {-salbutamol }}$ of $5.13 \mathrm{~L} / \mathrm{h}, \mathrm{CL}_{\mathrm{S} \text {-salbutamol }}$ of $2.78 \mathrm{~L} / \mathrm{h}$, and $V_{\mathrm{c}}$ of $2.76 \mathrm{~L}$ for a typical child weighing $15 \mathrm{~kg}$.

\subsection{Model Evaluation}

The model was evaluated using a bootstrap analysis. Median parameter values, as well as the 5th and 95th percentiles, were in agreement with the model estimations and errors. The distribution of errors was close to normal in the NPDEs (electronic supplementary material 2), with no significant trends in NPDE versus time and NPDE versus predictions.

\subsection{Dose Simulations}

The simulation in Fig. 3 shows that a loading dose leads to higher R- and S-salbutamol concentrations in the first hour after the start of intravenous salbutamol, compared with the infusion without a loading dose. The infusion rate of $0.5 \mu \mathrm{g} /$ $\mathrm{kg} / \mathrm{min}$ without a loading dose resulted in R-salbutamol concentrations of $22.2 \mu \mathrm{g} / \mathrm{L}$ and S-salbutamol concentrations

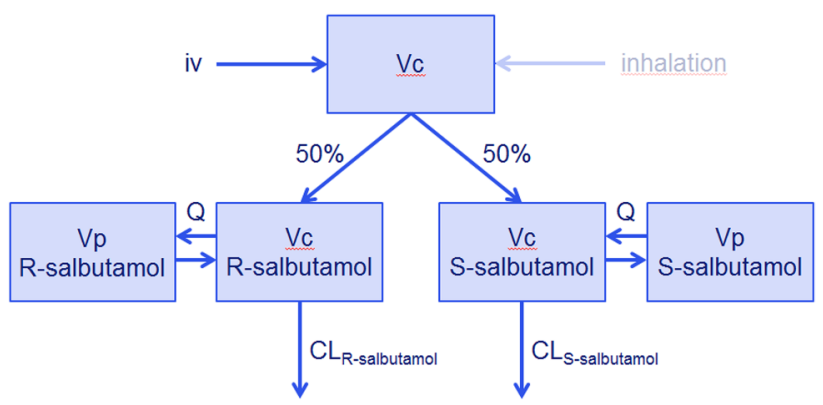

Fig. 1 Compartmental model. After intravenous infusion, salbutamol was rapidly split into 50\% R-salbutamol and 50\% S-salbutamol. Both had the same $V_{\mathrm{c}}, V_{\mathrm{p}}$ and $Q$ in a two-compartment system, as well as different values for CL. $C L$ clearance, $I V$ intravenous, $Q$ intercompartmental clearance, $V_{c}$ central volume of distribution, $V_{p}$ peripheral volume of distribution 
Table 2 Parameter estimations

\begin{tabular}{llllll}
\hline Parameter & Estimation & RSE $(\%)$ & IPV $(\%)$ & RSE (\%) & Shrinkage (\%) \\
\hline Baseline dose $(\mu \mathrm{g})$ & 448 & 25 & 99 & 20 & 15 \\
$\mathrm{CL}_{\mathrm{R}-\text { salbutamol }}(\mathrm{L} / \mathrm{h} / 70 \mathrm{~kg})$ & 16.3 & 12.4 & 42 & 15 & 19 \\
$\mathrm{CL}_{\text {S-salbutamol }}(\mathrm{L} / \mathrm{h} / 70 \mathrm{~kg})$ & 8.82 & 10.4 & 37 & 16 & 23 \\
$V_{\mathrm{c}}(\mathrm{L} / 70 \mathrm{~kg})$ & 12.9 & 65 & 281 & 21 & 9 \\
$Q(\mathrm{~L} / \mathrm{h} / 70 \mathrm{~kg})$ & 20.4 & 41.5 & & & \\
$V_{\mathrm{p}}(\mathrm{L} / 70 \mathrm{~kg})$ & 45.5 & 9.6 & & & 6 \\
Residual error $(\mu \mathrm{g} / \mathrm{L})$ & 0.351 & 21.9 & & & 6 \\
\hline
\end{tabular}

$V_{\mathrm{c}}, V_{\mathrm{p}}$ and $Q$ were identical for R- and S- salbutamol

A typical child weighing $15 \mathrm{~kg}$ will have a $\mathrm{CL}_{\mathrm{R} \text {-salbutamol }}$ of $16.3 \times(15 / 70)^{0.75}=5.13 \mathrm{~L} / \mathrm{h}, \mathrm{CL}_{\mathrm{S} \text {-salbutamol }}$ of $8.82 \times(15 / 70)^{0.75}=2.78 \mathrm{~L} / \mathrm{h}$, and $V_{\mathrm{c}}=12.9 \times(15 / 70)^{1}=2.76 \mathrm{~L}$

$C L$ clearance, $I P V$ interpatient variability, $Q$ intercompartmental clearance, $R S E$ relative standard error, $V_{c}$ central volume of distribution, $V_{p}$ peripheral volume of distribution
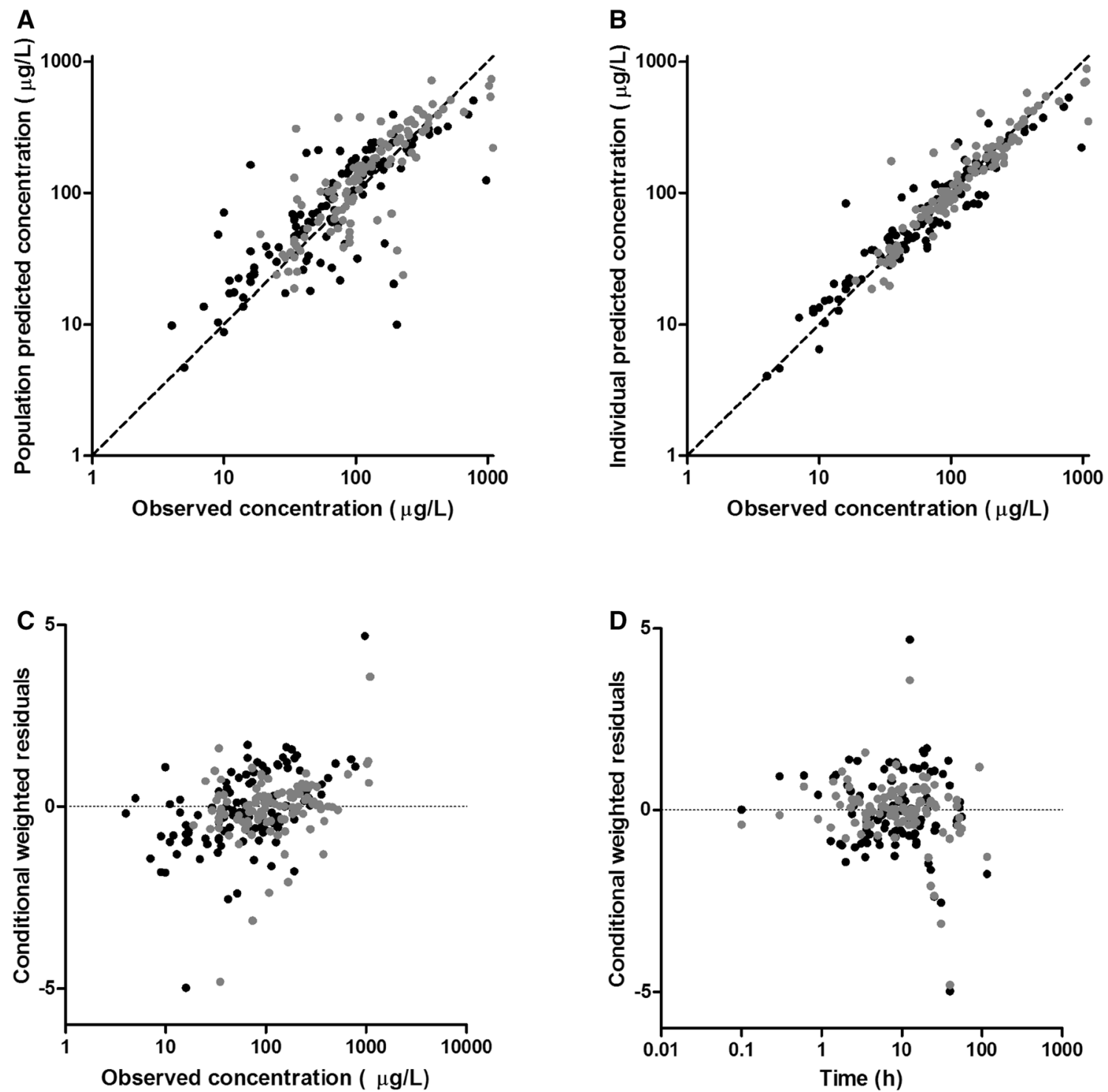

Fig. 2 Goodness-of-fit plots of R-salbutamol (black) and S-salbutamol (grey) 
of $29.2 \mu \mathrm{g} / \mathrm{L}$ at $15 \mathrm{~min}$ after the start of infusion therapy. With a loading dose, the R-salbutamol concentration was $36.7 \mu \mathrm{g} / \mathrm{L}$ and the $\mathrm{S}$-salbutamol concentration was $45.7 \mu \mathrm{g} / \mathrm{L}$ at $15 \mathrm{~min}$. Longer treatment with intravenous salbutamol results in increasing concentrations of mainly S-salbutamol.

\section{Discussion}

In this prospective study, we developed a population PK model of intravenous R- and S-salbutamol in children with status asthmaticus admitted to the intensive care unit. This model described the data well and showed that a loading dose seems valid in order to reach higher initial R-salbutamol concentrations with a possible therapeutic advantage. Furthermore, this model can be used to evaluate the PK-PD relationship of intravenous salbutamol.

Current dosing recommendations for intravenous salbutamol in children are not based on age-appropriate PK-PD data but are derived from adult data only [11]. There is no clear agreement about the initial dose of salbutamol required by the intravenous route in acute situations in children. For example, the Dutch pediatric formulary does not recommend a loading dose, but does recommend an initial continuous infusion of $0.1-10 \mu \mathrm{g} / \mathrm{kg} / \mathrm{min}$ (http://www.kinderformulari um.nl), while the British National Formulary recommends a bolus dose of $15 \mu \mathrm{g} / \mathrm{kg}$ (maximum $250 \mu \mathrm{g}$ ) over 5 min and a continuous infusion of $1-5 \mu \mathrm{g} / \mathrm{kg} / \mathrm{min}$. In contrast, the British guideline on the management of asthma [3] recommends

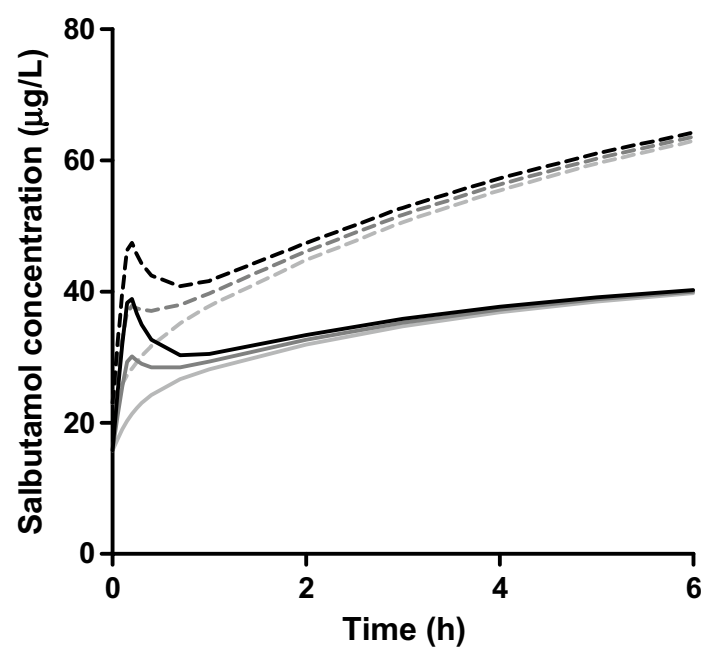

Fig. 3 Simulation of R-salbutamol (solid lines) and S-salbutamol (dotted lines) concentrations for a child weighing $15 \mathrm{~kg}$, after a continuous intravenous salbutamol infusion of $0.5 \mu \mathrm{g} / \mathrm{kg} / \mathrm{min}$ without a loading dose (light grey), or after a loading dose of $1.0 \mu \mathrm{g} / \mathrm{kg} / \mathrm{min}$ (dark grey) or $1.5 \mu \mathrm{g} / \mathrm{kg} / \mathrm{min}$ (black) over $10 \mathrm{~min}$. The initial concentration before infusion is almost $20 \mu \mathrm{g} / \mathrm{L}$ as a result of salbutamol inhalation administering the same bolus dose in $10 \mathrm{~min}$ rather than 5 min. Despite these guidelines, a survey in the UK and Ireland showed a threefold and tenfold variation in bolus doses and continuous infusion rates, respectively, reflecting the paucity of evidence to support dosing of intravenous salbutamol [17].

As intravenous salbutamol is delivered systemically, there are concerns that it is more likely to produce systemic adverse reactions related to interaction with non-airway $\beta 1$ receptors, such as tachycardia and dysrhythmias, than inhaled salbutamol. However, data on toxicity related to dose or serum concentrations are scarce. After multiple doses of inhaled salbutamol, plasma concentrations of $20-40 \mathrm{ng} /$ $\mathrm{mL}$ were found in adults and children [18-20]. In adults, salbutamol toxicity is associated with plasma concentrations $>30 \mathrm{ng} / \mathrm{mL}$ [21]; however, in children receiving intravenous salbutamol according to current guidelines, much higher systemic salbutamol concentrations (196-586 ng/mL) have been recorded $[22,23]$. In our study, we also found higher median plasma levels of R-salbutamol $(66 \mu \mathrm{g} / \mathrm{L}$, range 4-969 $\mu \mathrm{g} / \mathrm{L})$ and $\mathrm{S}-\mathrm{salbutamol}(108 \mu \mathrm{g} / \mathrm{L}$, range 19-1094 $\mu \mathrm{g} / \mathrm{L})$ than reported in adults, with no associated adverse reactions (data not shown), however our study population was small. There is a need to establish a therapeutic plasma concentration range in children.

After inhalation only, plasma levels were $24.5 \mu \mathrm{g} / \mathrm{L}$ (range 7-60 $\mu \mathrm{g} / \mathrm{L}$ ) for R-salbutamol and $49 \mu \mathrm{g} / \mathrm{L}$ (range 31-94 $\mu \mathrm{g} / \mathrm{L}$ ) for S-salbutamol, consistent with previous reports.

The necessity of an intravenous loading dose of salbutamol is currently under discussion. In adults, salbutamol has a half-life of 4-6 h after intravenous administration. As it takes approximately four half-lives to reach a plateau concentration if a drug is given as a constant infusion, $12-24 \mathrm{~h}$ is required to reach a plateau concentration, and subtherapeutic levels will be observed at the beginning of therapy, combined with excessive levels after several hours, if the infusion is titrated upwards according to clinical signs. An appropriate loading dose will result in faster target concentrations.

In children, the advice regarding loading dose is based on a few studies looking at the effect of a bolus dose of intravenous salbutamol 10-15 $\mu \mathrm{g} / \mathrm{kg}$ [24, 25] on asthma scores and hospital admission. These studies show a small effect on time to discharge from hospital or the PICU, duration of nebulization of salbutamol, and clinical asthma scores; however, no study used a validated asthma score and all studies had several methodological shortcomings. Furthermore, the patients in these studies did not receive a continuous infusion of intravenous salbutamol after the salbutamol loading dose.

Using our PK model, simulations of intravenous salbutamol in children with refractory status asthmaticus 
showed that a loading dose of salbutamol results in faster desired concentrations. In our simulations, we showed that a loading dose of $1.5 \mu \mathrm{g} / \mathrm{kg} / \mathrm{min}$ over $10 \min (15 \mu \mathrm{g} / \mathrm{kg})$, followed by a continuous infusion of salbutamol $0.5 \mu \mathrm{g} / \mathrm{kg} /$ $\mathrm{min}$, is required to reach an R-salbutamol concentration of $40 \mu \mathrm{g} / \mathrm{L}$ in a child weighing $15 \mathrm{~kg}$. Because of the half-life of salbutamol found in our model (for a $15 \mathrm{~kg}$ child, the half-life of R-salbutamol was $22 \mathrm{~min}$, and $41 \mathrm{~min}$ for S-salbutamol), a loading dose needs to be considered to quickly reach effective R-salbutamol concentrations in the early phase after the start of infusion therapy, thereby aiming for faster clinical improvement. Furthermore, a loading dose prevents accumulation of S-salbutamol, which is important as there are concerns that particularly high exposure to $\mathrm{S}$-salbutamol may have negative effects. In vitro, animal studies and studies in patients with mild asthma suggest that $\mathrm{S}$-salbutamol may increase bronchial hyperreactivity and promote smooth muscle contraction, leading to more respiratory distress [26-29], although this is under discussion [30]. As expected, we found a lower clearance of S-salbutamol compared with R-salbutamol. Knowledge of the PK of both R- and S-salbutamol is important to find the optimal dose for bronchodilation without adverse reactions.

Some limitations of our study should be acknowledged. In contrast to an earlier study [7], we found no effect of creatinine on salbutamol clearance, which is most likely due to the small number of patients and the absence of renal dysfunction in our cohort. Furthermore, we chose not to explore the relationship of genetic polymorphisms of the ADRB2 gene on salbutamol clearance as our sample size was very small.

An important strength of our study is that we took prior inhaled drugs into account in our model. Earlier studies did not measure plasma drug level after inhalation, while it is known that there is a significant degree of absorption of inhaled drugs. In clinical practice, children with severe asthma have had several inhaled doses of salbutamol prior to commencing intravenous drug therapy.

\section{Conclusions}

This PK model could be a first step towards evidence-based dosing of intravenous salbutamol in children. Simulations showed that a loading dose should be considered in children to quickly reach effective R-salbutamol concentrations in the early phase after the start of infusion therapy, thereby aiming for faster clinical improvement. As a next step, the efficacy of a loading dose of intravenous salbutamol should be studied in children with severe asthma, in a randomized controlled trial, compared with placebo (NCT03493503).

\section{Compliance with Ethical Standards}

Funding No external funding was used in the preparation of this manuscript.

Conflict of interest Nienke J. Vet, Brenda C.M. de Winter, Muriel Koninckx, Shelley A. Boeschoten, Annemie L.M. Boehmer, Jacintha T. Verhallen, Frans B. Plötz, Anja A. Vaessen-Verberne, Bart C.H. van der Nagel, Catherijne A.J. Knibbe, Corinne M.P. Buysse, Saskia N. de Wildt, Birgit C.P. Koch, and Matthijs de Hoog declare they have no potential conflicts of interest that might be relevant to the contents of this manuscript.

Open Access This article is distributed under the terms of the Creative Commons Attribution-NonCommercial 4.0 International License (http://creativecommons.org/licenses/by-nc/4.0/), which permits any noncommercial use, distribution, and reproduction in any medium, provided you give appropriate credit to the original author(s) and the source, provide a link to the Creative Commons license, and indicate if changes were made.

\section{References}

1. Hartman ME, Linde-Zwirble WT, Angus DC, Watson RS. Trends in admissions for pediatric status asthmaticus in New Jersey over a 15-year period. Pediatrics. 2010;126:e904-11.

2. Boeschoten SA, Buysse CMP, Merkus P, van Wijngaarden JMC, Heisterkamp SGJ, de Jongste JC, SKIC Dutch Collaborative PICU Research Network, et al. Children with severe acute asthma admitted to Dutch PICUs: a changing landscape. Pediatr Pulmonol. 2018;53(7):857-65.

3. British guideline on the management of asthma: a national clinical guideline. 2016. Available at: https://www.brit-thoracic.org. uk/document-library/clinical-information/asthma/btssign-asthm a-guideline-2016/.

4. Rehder KJ. Adjunct therapies for refractory status asthmaticus in children. Respir Care. 2017;62:849-65.

5. Travers AH, Milan SJ, Jones AP, Camargo CA Jr, Rowe BH. Addition of intravenous beta(2)-agonists to inhaled beta(2)-agonists for acute asthma. Cochrane Database Syst Rev. 2012;(12):CD010179.

6. Boulton DW, Fawcett JP. Enantioselective disposition of salbuta$\mathrm{mol}$ in man following oral and intravenous administration. Br J Clin Pharmacol. 1996;41:35-40.

7. Maier G, Rubino C, Hsu R, Grasela T, Baumgartner RA. Population pharmacokinetics of (R)-albuterol and (S)-albuterol in pediatric patients aged 4-11 years with asthma. Pulm Pharmacol Ther. 2007;20:534-42.

8. Boulton DW, Fawcett JP. The pharmacokinetics of levosalbutamol: what are the clinical implications? Clin Pharmacokinet. 2001;40:23-40.

9. Shann F. Dose of intravenous infusions of terbutaline and salbutamol. Crit Care Med. 2000;28:2179-80.

10. Sellers WF, Messahel B. Rapidly repeated intravenous boluses of salbutamol for acute severe asthma. Anaesthesia. 2003;58:680-3.

11. Starkey ES, Mulla H, Sammons HM, Pandya HC. Intravenous salbutamol for childhood asthma: evidence-based medicine? Arch Dis Child. 2014;99:873-7.

12. Qureshi F, Pestian J, Davis P, Zaritsky A. Effect of nebulized ipratropium on the hospitalization rates of children with asthma. N Engl J Med. 1998;339:1030-5. 
13. Eggink H, Brand P, Reimink R, Bekhof J. Clinical scores for dyspnoea severity in children: a prospective validation study. PLoS One. 2016;11:e0157724.

14. Keizer RJ, Karlsson MO, Hooker A. Modeling and simulation workbench for NONMEM: tutorial on Pirana, PsN, and Xpose. CPT Pharmacometrics Syst Pharmacol. 2013;2:e50.

15. Boxenbaum H. Interspecies pharmacokinetic scaling and the evolutionary-comparative paradigm. Drug Metab Rev. 1984;15:1071-121.

16. de Winter B, de Hoog M, Vet NJ, Dunk-Craaijo J, Koch BCP, de Wildt SN. High albuterol plasma concentrations caused by fingerprick blood following inhalation on the ICU [abstract]. In: 14th international congress of therapeutic drug monitoring and clinical toxicology; 11-15 Oct 2015: Rotterdam.

17. Lyttle MD, O'Sullivan R, Doull I, Hartshorn S, Morris I, Powell CV. Variation in treatment of acute childhood wheeze in emergency departments of the United Kingdom and Ireland: an international survey of clinician practice. Arch Dis Child. 2015;100:121-5.

18. Janson C, Boe J, Boman G, Mossberg B, Svedmyr N. Bronchodilator intake and plasma levels on admission for severe acute asthma. Eur Respir J. 1992;5:80-5.

19. Rotta ET, Amantea SL, Froehlich PE, Becker A. Plasma concentrations of salbutamol in the treatment of acute asthma in a pediatric emergency. Could age be a parameter of influence? Eur J Clin Pharmacol. 2010;66:605-10.

20. Evans ME, Paterson JW, Richards AJ, Walker SR. Pharmacokinetics of inhaled salbutamol in asthmatic patients. Br J Pharmacol. 1971;43:466P-7P.

21. Regenthal R, Krueger M, Koeppel C, Preiss R. Drug levels: therapeutic and toxic serum/plasma concentrations of common drugs. J Clin Monit Comput. 1999;15:529-44.
22. Penna AC, Dawson KP, Manglick P, Tam J. Systemic absorption of salbutamol following nebulizer delivery in acute asthma. Acta Paediatr. 1993;82:963-6.

23. Bohn D, Kalloghlian A, Jenkins J, Edmonds J, Barker G. Intravenous salbutamol in the treatment of status asthmaticus in children. Crit Care Med. 1984;12:892-6.

24. Browne GJ, Penna AS, Phung X, Soo M. Randomised trial of intravenous salbutamol in early management of acute severe asthma in children. Lancet. 1997;349:301-5.

25. Browne GJ, Trieu L, Van Asperen P. Randomized, double-blind, placebo-controlled trial of intravenous salbutamol and nebulized ipratropium bromide in early management of severe acute asthma in children presenting to an emergency department. Crit Care Med. 2002;30:448-53.

26. Henderson WR Jr, Banerjee ER, Chi EY. Differential effects of (S)- and (R)-enantiomers of albuterol in a mouse asthma model. J Allergy Clin Immunol. 2005;116:332-40.

27. Auais A, Wedde-Beer K, Piedimonte G. Anti-inflammatory effect of albuterol enantiomers during respiratory syncytial virus infection in rats. Pediatr Pulmonol. 2005;40:228-34.

28. Agrawal DK, Ariyarathna K, Kelbe PW. (S)-albuterol activates pro-constrictory and pro-inflammatory pathways in human bronchial smooth muscle cells. J Allergy Clin Immunol. 2004;113:503-10.

29. Nowak R, Emerman C, Hanraban JP, Parsey MV, Hanania NA, Claus R, et al. A comparison of levalbuterol with racemic albuterol in the treatment of acute severe asthma exacerbations in adults. Am J Emerg Med. 2006;24:259-67.

30. Barnes PJ. Treatment with (R)-albuterol has no advantage over racemic albuterol. Am J Resp Crit Care Med. 2006;9:969-72.

\section{Affiliations}

\section{Nienke J. Vet ${ }^{1}$ (1) - Brenda C. M. de Winter ${ }^{2} \cdot$ Muriel Koninckx $^{3}$. Shelley A. Boeschoten ${ }^{1} \cdot$ Annemie L. M. Boehmer ${ }^{4}$. Jacintha T. Verhallen ${ }^{5} \cdot$ Frans B. Plötz ${ }^{6}$. Anja A. Vaessen-Verberne ${ }^{7}$ Bart C. H. van der Nagel ${ }^{2}$. Catherijne A. J. Knibbe ${ }^{8}$. Corinne M. P. Buysse ${ }^{1}$. Saskia N. de Wildt ${ }^{1,9} \cdot$ Birgit C. P. Koch $^{2} \cdot$ Matthijs de Hoog $^{1}$}

1 Pediatric Intensive Care Unit, Department of Pediatrics, Erasmus MC-Sophia Children's Hospital, Dr. Molewaterplein 40, 3015 GD Rotterdam, The Netherlands

2 Department of Hospital Pharmacy, Erasmus MC, Rotterdam, The Netherlands

3 Pediatric Intensive Care, Middelheim Ziekenhuis, Antwerp, Belgium

4 Department of Pediatrics, Maasstad Hospital, Rotterdam, The Netherlands

5 Department of Pediatrics, Franciscus Gasthuis and Vlietland, Rotterdam, The Netherlands
6 Department of Pediatrics, Tergooi Hospital, Blaricum, The Netherlands

7 Department of Pediatrics, Amphia Hospital, Breda, The Netherlands

8 Division of Pharmacology, Leiden Academic Centre for Drug Research, Leiden, The Netherlands

9 Department of Pharmacology and Toxicology, Radboud University, Nijmegen, The Netherlands 